Vol 11, Issue 7, 2018

\title{
A STEREOLOGICAL STUDY OF HIPPOCAMPUS IN EXPERIMENTAL EPILETIC RAT MODEL TREATED WITH ACORUS CALAMUS AND BETA-ASARONE
}

\author{
VENKATARAMANIAH $C^{1}$, MARY ANTONY PRABA A ${ }^{2 *}$ \\ ${ }^{1}$ Department of Anatomy, Tagore Dental College and Hospital, Chennai, Tamil Nadu, India. ${ }^{2}$ Department of Anatomy, Tagore Medical \\ College and Hospital, Chennai, Tamil Nadu, India. Email: fio7rio@yahoo.co.in
}

Received: 12 February 2018, Revised and Accepted: 13 April 2018

\section{ABSTRACT}

Objective: Epilepsy is the fourth most prevalent neurodegenerative disorder that affects about 1-2\% of people round the world. Epilepsy cannot be cured even with modern medication, but the medications can control the seizures. Even this cannot be achieved in nearly $30 \%$ of epileptic population. At this point, we felt the need of some natural supplements to protect the nervous system against neurodegeneration and so created an equivalent model of epilepsy with kainic acid lesion and studied the novel role of Acorus calamus in protecting the neurons.

Methods: For this study, we divided the animals into four groups, based on the drugs used. We also produced a stereotaxic model of epilepsy by inducing kainic acid into the right hippocampus of all the animals except CO (control) group. Then, we conducted a stereological study both on the $2^{\text {nd }}$ and $7^{\text {th }}$ day after surgery, to rule out the neuroprotective and neuroregenerative ability of the drugs employed.

Results: The results were amazing. Stereological study on the $2^{\text {nd }}$ day revealed a very large lesion on the hippocampus of lesion control (LC) animals, and the lesion was very much smaller in both drug group animals. On the $7^{\text {th }}$ day also the LC animals showed a large lesion, but the lesion on the drug group animals diminished due to a number of new cells, probably of neurons grown in the place of lesion.

Conclusion: The results proved the neuroprotective and regenerative ability of both drugs, but as a fact, beta-asarone had an upper hand in this study.

Keywords: Epilepsy, Seizure, Neurodegeneration, Stereotaxic model, Kainic acid.

(c) 2018 The Authors. Published by Innovare Academic Sciences Pvt Ltd. This is an open access article under the CC BY license (http://creativecommons. org/licenses/by/4. 0/) DOI: http://dx.doi.org/10.22159/ajpcr.2018.v11i7.25249

\section{INTRODUCTION}

Epilepsy is a neurodegenerative disorder characterized by seizure, affecting around $1-2 \%$ of world's population. It is of two types the generalized and focal epilepsy. Mesial temporal lobe epilepsy (MTLE) is the major form of focal epilepsy, and hippocampal sclerosis is the most common cause of MTLE. Modern therapies can control epilepsy, but they cannot cure it completely. Over 30\% people with epilepsy do not have seizure control even with best available treatment [1].

The hippocampus, which is present inside the mesial temporal lobe, plays important roles in short-term, long-term memory, spatial navigation, and initial learning [2]. Hippocampal sclerosis is the most common type of tissue damage in temporal lobe epilepsy. Hippocampal damage was a frequent result in experimental settings [3], where artificial repetitive seizures induced in animals.

According to the legends of Ayurveda such as Charaka and Susruta (600BC), Acorus calamus (AC) was a drug of choice for epilepsy, promotes intellect in children, memory, and used to boost up the activities of brain in the form of brain tonic. The good olden medicinal ghee or the nervine tonic had AC, Bacopa monnieri, and Alpinia speciosa and used for mostly all the neuronal disabilities [4]. The rhizome has around $1.5-3.5 \%$ of essential oil [5]. Aromatherapists use this oil for curing memory loss, epilepsy, and shock [6].

The extract of $\mathrm{AC}$ has beta-asarone (BA) as one of the major phytochemicals. BA is a powerful central nervous system stimulant and Waller's British Herbal says: It is of great service in all nervous complaints, vertigoes, and headaches. Oral administration of BA said to improve cognitive function by suppressing neuronal apoptosis in the hippocampus of beta-amyloid injected rats [7].
All the above said scenarios instilled the idea of creating a model of epilepsy and hauled us to study the preventive and therapeutic upshots of AC and BA.

\section{METHODS}

We created a lesion model by injecting kainic acid locally into the right hippocampus with the help of stereotaxic frame. We purchased the frame from INCO (Instruments and Chemicals Pvt., Ltd.) Ambala, Haryana.

\section{Kainic acid}

We purchased Kainic acid from Cayman Chemicals - USA and dissolved it in $0.9 \% \mathrm{NaCl}$ (Sodium chloride) [8] just before lesion surgery to get $1 \mu \mathrm{g}$ Kainic acid in $1 \mu \mathrm{l}$. Kainic acid is an analog of glutamic acid and a potent neuroexcitotoxin. Previous researchers observed free radical formation in brain, $1 \mathrm{~h}$ after kainic acid administration [9]. According to Manikandan et al., reactive oxygen species are the major risk factors [10] that promote neurodegeneration [11], and AC is very well- known for its radical scavenging activity [12].

\section{Ethanolic extract of AC preparation}

We prepared ethanolic extract of AC by soxhletion method [5]. Elayaraja et al. proved that ethanolic extract has more antioxidant activity than any other extracts of AC.

We decided the dosages of ethanolic extract of $\mathrm{AC}$ and BA by sticking with the lethal dose 50 of the substances.

\section{BA}

We purchased BA from Sigma-Aldrich Ltd., St. Louis, USA.

We started giving the drugs 10 days before lesion surgery and continued till the end of the study after lesion to analyze the protective nature as 
well as the therapeutic role of them in hippocampus and given around 10 'o clock every day in IP.

\section{Animals}

For this study, we housed adult male Sprague Dawley rats (200-250 g) under standard laboratory condition and maintained in compliance with strict institutional guidance and ethical permission. We maintained the room environment at $20^{\circ} \mathrm{C} \pm 2^{\circ} \mathrm{C}$; alternating $12 \mathrm{~h}$ lightdark cycle with food and water ad libitum took greatest effort to lower the unwanted stress to the animals and cut the number of animals used for this study. We used four groups of animals for this study with six animals in each group. They are CO (control group), lesion control (LC), AC 35 (AC ethanolic extract $35 \mathrm{mg} / \mathrm{kg}$ body weight), and BA 20 (BA $20 \mathrm{mg} / \mathrm{kg}$ body weight). We used tween $803 \%$ solution as a vehicle [13] to dissolve and to make different concentrations of drugs and adjusted the volume to $1 \mathrm{ml}$ for each animal.

\section{Stereological study to measure the damaged area}

We conducted a stereological study to find out the degenerated area in hippocampus and used a $1 \mathrm{~cm}^{2}$ grid of square lattice containing intersections, known as reticule for this quantitative study. We fixed the reticule in the eyepiece of a light microscope and used it to calculate the degenerated area.

We conducted the study both on the $2^{\text {nd }}$ and $7^{\text {th }}$ day after lesion surgery to rule out the protective effect ( $2^{\text {nd }}$ day) and the regenerative ability ( $7^{\text {th }}$ day) of the drugs employed, as a few studies showed the regeneration of nerve cells in the hippocampal region [14] even in adult human. The brain tissues collected on the $2^{\text {nd }}$ day processed and stained with Trypan blue live cell exclusion technology and on the $7^{\text {th }}$ day stained with Vectra staining technology with ABC-elite kit from Japan.

\section{Methodology}

The reticule was placed into the eyepiece of the light microscope

The grids of the lattice fixed in focus with the degenerated area of brain.

The corners of the grids that hit the degenerated area counted ( $\mathrm{P}=$ number of points hitting the profile).

The total corner points over the test area also counted $(\mathrm{Pt}=$ total number of reference points).

Degenerated area or area fraction degenerated $=\mathrm{P} / \mathrm{Pt}$

\section{Example}

\section{Calculation}

Number of points hit the degenerated area (profile) $=\mathrm{P}=56$

Number of points hit over the test area (total number of reference points) $=\mathrm{Pt}=373$

Conversion factor $=373 / 100=3.73$

Degenerated area or area fraction degenerated $=56 / 3.73=15.01 \%$

The result showed $15.01 \%$ degenerated area.

\section{RESULTS}

Limbic status epilepticus and convulsion, the results of LC group in the $1^{\text {st }} \mathrm{h}$ after lesion surgery. Over the following days, the animals were ferocious and that made handling them tough. The drug group animals did not show any gross epileptic changes as both drugs were very effective in protecting from the deleterious effects of kainic acid.

Stereology for analyzing the area of damage

This parameter deals the area fraction damaged due to kainic acid lesion and so the protective effect of the drugs in hippocampus with the help of a reticule on $\times 10$ magnification.
Fraction of degenerated area - on the $2^{\text {nd }}$ day of lesion

The CO animals showed normal histological pattern of hippocampus. The LC group animals had a very large lesion $(15.36 \pm 1.42 \%)$ in the hippocampal region. The AC 35 group animals showed only a small lesion with $7.09 \pm 1.01 \%$ damaged area that was much smaller when compared with LC group. With the animals treated with BA 20, only a very small lesion with $5.89 \pm 0.35 \%$ degenerated area observed. This was much less when compared with LC group.

These results clarify (Fig. 1) that the drug BA 20 was more effective against nerve cell degeneration in comparison with AC 35.

\section{Fraction of degenerated area - on the $7^{\text {th }}$ day of lesion}

On the $7^{\text {th }}$ day also the hippocampus belongs to LC group had a very large lesion with $15.05 \pm 0.76 \%$ damaged area and was equal with the damaged fraction of LC group on the $2^{\text {nd }}$ day. However, the degenerated area reduced in the drug groups AC $35(4.82 \pm 0.38 \%)$ and BA $20(4.28 \pm 0.37 \%)$, on the $7^{\text {th }}$ day as the lesion area covered with newly formed cells.

For BA 20 group animals, the lesion was almost covered with newly formed cells (Fig. 2), and they also formed connections with the nearby neurons.

We have drawn a bar diagram to compare the degenerated area among the $2^{\text {nd }}$ and $7^{\text {th }}$ day to analyze the preventive and therapeutic roles of drugs employed.

The LC group animals have shown near equal degenerated area both on the $2^{\text {nd }}$ and $7^{\text {th }}$ days of lesion. In AC 35 animal groups, the degenerated area got reduced on the $7^{\text {th }}$ day than the $2^{\text {nd }}$ day. The degenerated area was the smallest with BA 20 group on the $2^{\text {nd }}$ day and was further reduced (Fig. 3 ) on the $7^{\text {th }}$ day too due to the regeneration of large number of nerve cells.

\section{DISCUSSION}

Research in China has shown the essential oil of AC rhizome had neuroprotective activity [15]. Legradi, 2010 [16], studied the adult

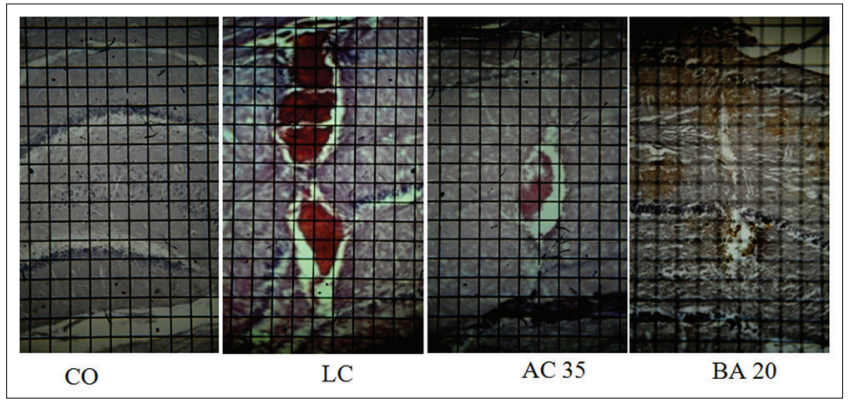

Fig. 1: The comparison of fraction of degenerated area in hippocampus belongs to CO, lesion control, Acorus calamus 35, and BA 20 on the $2^{\text {nd }}$ day of lesion ( $\times 10$ magnification)

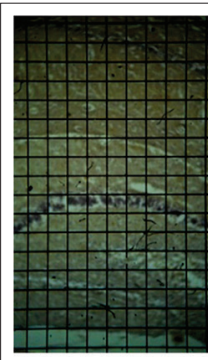

$\mathrm{CO}$

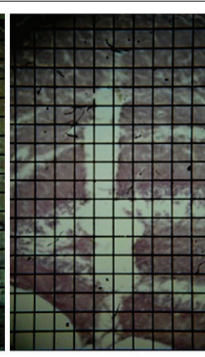

LC

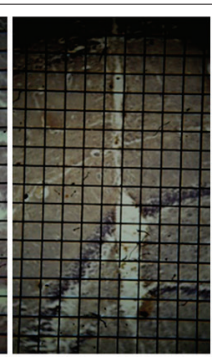

AC 35

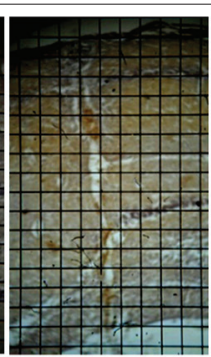

BA 20
Fig. 2: The comparison of fraction of degenerated area in hippocampus belongs to CO, lesion control, Acorus calamus 35, and BA 20 on the $7^{\text {th }}$ day of lesion ( $\times 10$ magnification) 


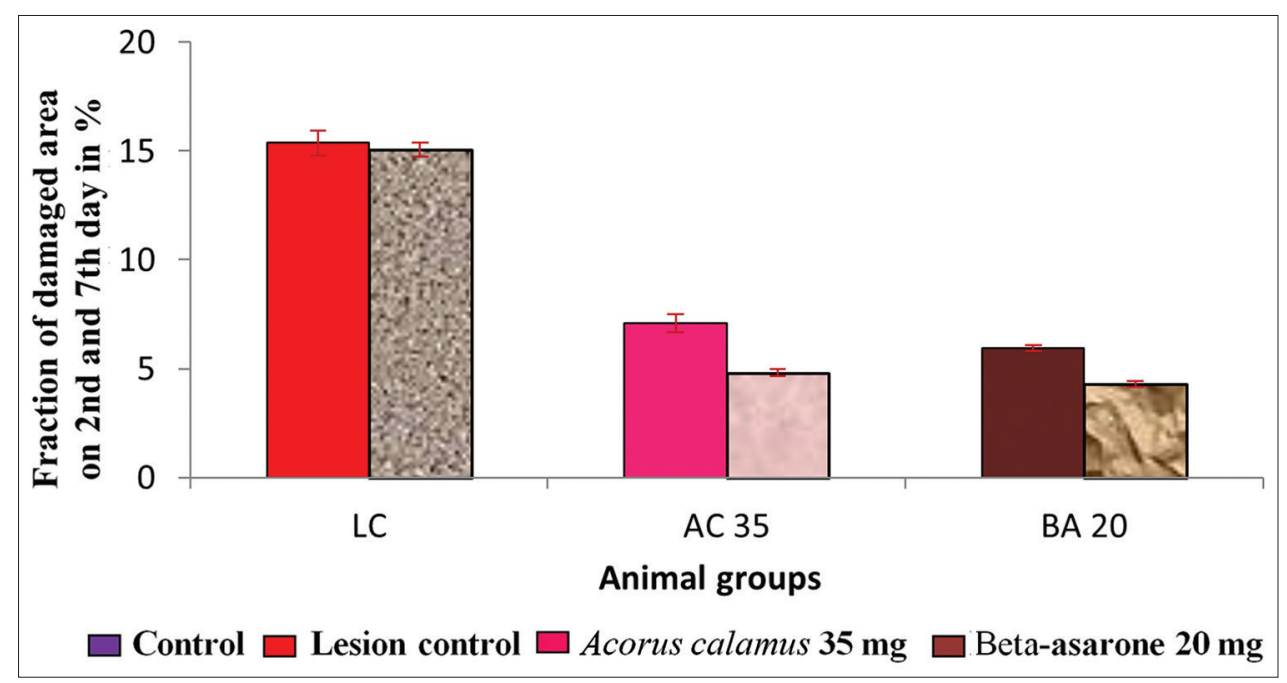

Fig. 3: The comparison of degenerated area in the hippocampus of rats on the $2^{\text {nd }}$ and $7^{\text {th }}$ day of lesion

hippocampal slice cultures as a model of apoptotic aspects of neurodegeneration and used Trypan blue staining to analyze the slice viability. Here, also, we used the same technique live cell exclusion technology to analyze the dead cells and so the degenerated area. In LC group animals, the hippocampus showed a very lesion stained by Trypan blue both on the $2^{\text {nd }}$ and $7^{\text {th }}$ day as there were no drugs either to prevent the neuronal damage or to stimulate new cells to form. The AC 35 group animals exhibited a comparatively smaller Trypan bluestained area, but it was smallest in BA 20 group that stated the efficacy of the drugs and confirmed the rolls of both drugs in preventing nerve cell degeneration.

Singh, 2008 [17], described that AC can delay brain aging and stimulate regeneration of neurons. Nakatomi et al., 2002 [15], proved stimulation of endogenous progenitors led to the massive regeneration of hippocampal pyramidal neurons after ischemic brain injury. Bendel et al., 2005 [18], suggested the endogenous capacity of the brain to form new nerve cells after injury and proved regeneration of neurons in the CA1 hippocampal region after ischemic insult. This present study demonstrated regeneration of nerve cells in the hippocampus of animals belonging to both AC 35 and BA 20 that was the reason for the reduction in the damage area fraction on the $7^{\text {th }}$ day in both the drug groups.

\section{CONCLUSION}

Although there were few new cells on the periphery of the lesion in LC animals on the $7^{\text {th }}$ day, the degenerated area was equal with the $2^{\text {nd }}$ day as the newly formed cells were negligible. The degenerated area belongs to AC 35 was very much reduced on the $7^{\text {th }}$ day as more new cells grown in lesion. In higher magnification, they appeared more like big multipolar nerve cells (Fig. 4) with visible processes.

Lesion on BA 20 animals was almost diminished (Fig. 5) on the $7^{\text {th }}$ day due to large number of newly formed cells. The cells were more like neurons that made connections with the nearby neurons.

From all the above said, we came to a conclusion that both the drugs AC 35 and BA 20 had a very good action on hippocampus in terms of protection with a step ahead action with BA 20 . This study will be further continued to confirm whether the newly formed cells are glia or nerve cells.

As prevention is always better than cure, we end that both $\mathrm{AC}$ and $\mathrm{BA}$ can effectively use as food supplements in a minimal amount to prevent neurodegeneration as degeneration of neurons is the major cause for most of the nervous system related incurable disorders.

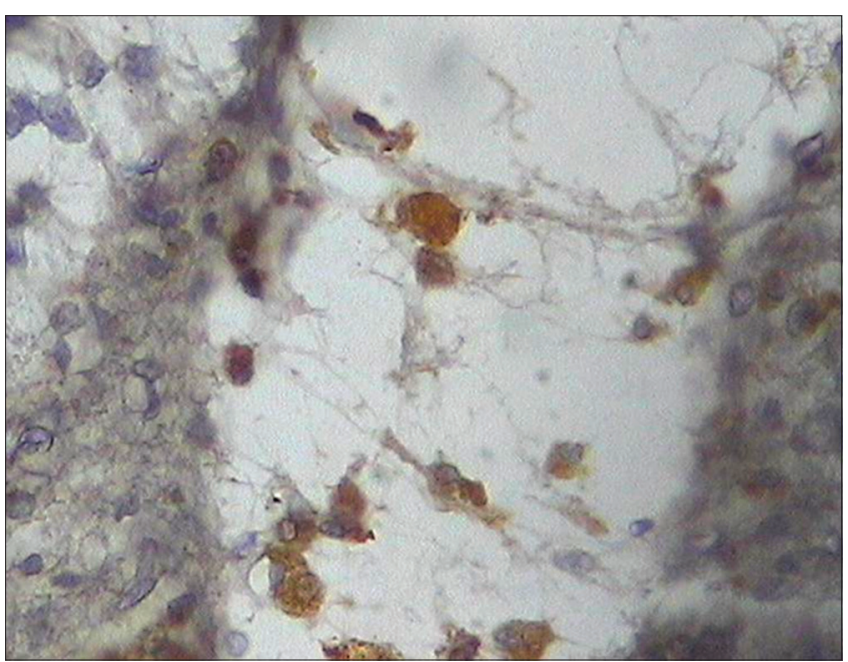

Fig. 4: The large newly formed cells with processes in lesion area belongs to Acorus calamus 35 group on the $7^{\text {th }}$ day $(\times 40$ magnification)

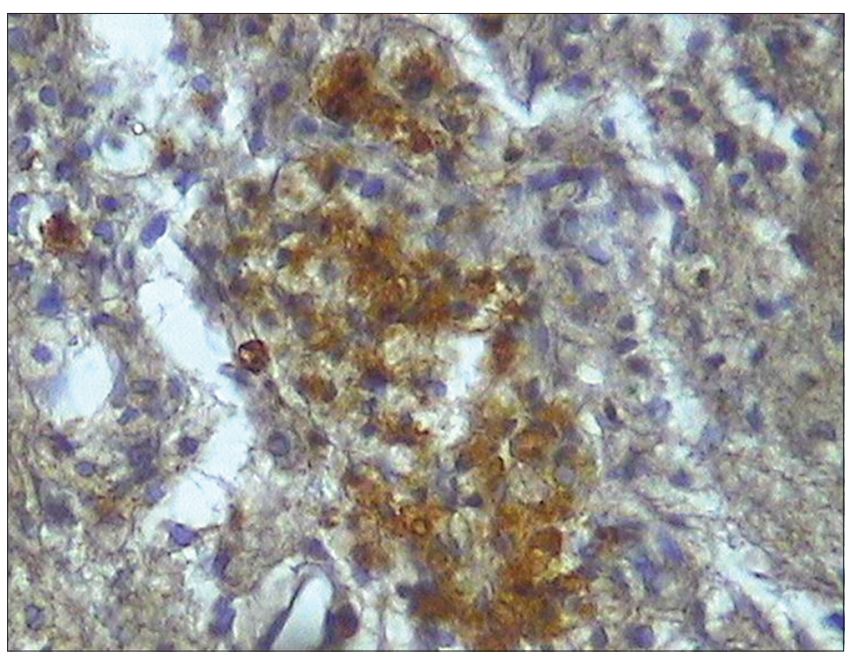

Fig. 5: Many large newly formed cells with processes covered the area of lesion belongs to beta-asarone 20 group on the $7^{\text {th }}$ day ( $\times 40$ magnification) 


\section{ACKNOWLEDGMENT}

We are very much thankful to Dr. Venkatraman, former director of CLBAID Mehta College of Pharmacy for his valuable guidance on the course of this study. We are also thankful to the technical staffs belongs to the Department of Anatomy, Tagore Medical College for their kind help.

\section{AUTHOR'S CONTRIBUTIONS}

The whole work done was by Dr. Venkataramaniah. C, the author of this manuscript. Assistance of staining the histology sections and bar diagrams was done by the corresponding author Dr. Mary Antony Praba. A.

\section{CONFLICTS OF INTEREST STATEMENT}

The authors declare that they have no conflicts of interest.

\section{REFERENCES}

1. Sidig A, Hussein A, Yassien F, Hamed A, Adil O, Saad M. et al. The pattern of clinical presentation of epilepsy among adolescence Sudanese epileptic patients. J Neurosci Behav Health 2011;3:1-7.

2. Burgess N. The hippocampus, space, and viewpoints in episodic memory. Quarterl J Exp Psycho 2002;55:1057-80.

3. Sufian FA, Ang LC. Neuropathology of temporal lobe epilepsy. Epilepsy Res Treat 2012;2012:13.

4. Khare CP. Indian Herbal Remedies: Rational Western Therapy, Ayur and Other Tradi Usage Botany. New York: Springer; 2004. p. 90.

5. Elayaraja A, Vijayalakshmi M, Devalarao G. In vitro free radical scavenging activity of various root and rhizome extracts of Acorus calamus linn. Int J Pharm Biosci 2010;1:301.

6. Available from: http://www.aromatherapies.net/blog/calamus-sweetflag-oil-acorus-calamus.html.

7. Liu L, Fang YQ. Analysis of the distribution of $\beta$-asarone in rat hippocampus, brainstem, cortex and cerebellum with gas chromatography-mass spectrometry (GC-MS). J Med Plants Res
2011;5:1728-34.

8. Praba AM, Venkatramaniah C, Kavitha G. Free radical scavenging and neuroprotective effect of Withania Somnifera and it's active principle withanolide a in huntington's chorea model of rats. J Pharm Biomed Sci 2014;4:674-8

9. Sun AY, Cheng Y, Bu Q Oldfield F. The biochemical mechanisms of the excitotoxicity of kainic acid. Free radical formation. Mol Chem Neuropathol 1992;17:51-63.

10. Manikandan S, Srikumar R, Parthasarathy NJ. Protective effect of Acorus calamus linn on free radical scavengers and lipid peroxidation in discrete regions of brain against noise stress exposed rat. Biol Pharm Bull 2005;28:2327-30.

11. Rajan S, Gokila M, Jency P, Brindha P, Sujatha RK. Antioxidant and phytochemical properties of Aegle marmelos fruit pulp. Int J Curr Pharm Res 2011;3:65-70.

12. Manjua S, chandrana RP, Shajib PK, Nair GA. In vitro free radical scavenging potential of Acorus calamus L. Rhizome from Kuttanad wetlands, Kerala, India. Int J Pharm Pharm Sci 2013;5:376-80.

13. Dandia PC, Menon MK. Action of Asarones in behavior stress and hyperpyrexia and it's interaction with central stimulants. J Pharm Exp Ther 1964;42:145-6.

14. Nakatomi H, Kuriu T, Okabe S, Yamamoto S, Hatano O, Kawahara N. Regeneration of hippocampal pyramidal neurons after ischemic brain injury by recruitment of endogenous neural progenitors. Cell 2002;110:429-41.

15. Meena A, Rao MM, Singh A, Kumari S. Physicochemical and preliminary phytochemical studies on the rhizome of Acorus calamus linn. Int J Pharm Pharm Sci 2010;2:130-1.

16. Legradi A, Varszegi S, Szigeti C, Gulya K. Adult rat hippocampal slices as in vitro models for neurodegeneration: Studies on cell viability and apoptotic processes. Brain Res Bull 2011;84:39-44.

17. Singh IB. TB of Human Neuro Anatomy. New Delhi: Jaypee Brothers Publishers; 2008. p. 245-8.

18. Bendel O, Bueters T, Euler MV, Ogren O, Sandin J, Euler G. Reappearance of hippocampal CA1 neurons after ischemia is associated with recovery of learning and memory. J Cereb Blood Flow Metabol 2005;25:1586-95. 